\title{
The impact of land use/land cover scale on modelling urban ecosystem services
}

\author{
Darren R. Grafius (iD $\cdot$ Ron Corstanje • \\ Philip H. Warren • Karl L. Evans • \\ Steven Hancock • Jim A. Harris
}

Received: 28 September 2015/ Accepted: 29 December 2015/Published online: 19 January 2016

(C) The Author(s) 2016. This article is published with open access at Springerlink.com

\begin{abstract}
Context Urbanisation places increasing stress on ecosystem services; however existing methods and data for testing relationships between service delivery and urban landscapes remain imprecise and uncertain. Unknown impacts of scale are among several factors that complicate research. This study models ecosystem services in the urban area comprising the towns of Milton Keynes, Bedford and Luton which together represent a wide range of the urban forms present in the UK.

Objectives The objectives of this study were to test (1) the sensitivity of ecosystem service model outputs to the spatial resolution of input data, and (2) whether any resultant scale dependency is constant across different ecosystem services and model approaches (e.g. stock- versus flow-based).
\end{abstract}

D. R. Grafius $(\bowtie) \cdot$ R. Corstanje · J. A. Harris School of Energy, Environment and Agrifood, Cranfield University, Cranfield, Bedfordshire MK43 0AL, UK

e-mail: d.r.grafius@cranfield.ac.uk

P. H. Warren · K. L. Evans

Department of Animal and Plant Sciences, University of Sheffield, Sheffield S10 2TN, UK

S. Hancock

Environment and Sustainability Institute, University of Exeter, Penryn, Cornwall TR10 9FE, UK
Methods Carbon storage, sediment erosion, and pollination were modelled with the InVEST framework using input data representative of common coarse $(25 \mathrm{~m})$ and fine $(5 \mathrm{~m})$ spatial resolutions.

Results Fine scale analysis generated higher estimates of total carbon storage (9.32 vs. $7.17 \mathrm{~kg} \mathrm{~m}^{-2}$ ) and much lower potential sediment erosion estimates (6.4 vs. $18.1 \mathrm{Mg} \mathrm{km}^{-2}$ year $^{-1}$ ) than analyses conducted at coarser resolutions; however coarse-scale analysis estimated more abundant pollination service provision.

Conclusions Scale sensitivities depend on the type of service being modelled; stock estimates (e.g. carbon storage) are most sensitive to aggregation across scales, dynamic flow models (e.g. sediment erosion) are most sensitive to spatial resolution, and ecological process models involving both stocks and dynamics (e.g. pollination) are sensitive to both. Care must be taken to select model data appropriate to the scale of inquiry.

Keywords Ecosystem services - Urban - Model · Natural capital · Scale $\cdot$ InVEST $\cdot$ Pollination · Erosion · Carbon · England

\section{Introduction}

The influence of scale has long been an important topic in ecological research, and it is well-documented that 
many spatial patterns in ecology are highly scale dependent (e.g. Wiens 1989; Elith and Leathwick 2009; Chave 2013). Ecosystem services are dependent on dynamic processes that act and interact at different scales; however a clear understanding of how best to study such services and account for their complex spatial and temporal relationships remains the subject of ongoing research (e.g. Konarska et al. 2002; Andersson et al. 2015; Holt et al. 2015). In both the measurement and modelling of such services, tradeoffs between accuracy and feasibility exist when selecting a scale of inquiry, and finding an optimal balance depends on research goals and decisionmaking contexts (Schröter et al. 2015). There are numerous challenges in modelling the ecosystem service provision of a landscape, but principal among them are:

(1) the ability to specify the relationship between a particular element of the environment (e.g. type of land cover) and the generation of a particular service; and,

(2) possessing information about the composition of the environment at the appropriate scale and resolution.

The first of these primarily concerns our understanding of the key processes that underpin services, and how these work in different ecosystems, i.e. the mechanisms used in the modelling process. The second, the scale and classification of data on the environment, concerns the nature of input data, and is our focus here.

When representing natural systems and their services as spatial data, the resolution may not be appropriate or optimal for the service under study which may in turn lead to misrepresentations of ecosystem service provision, however well-suited the model used to generate it (Konarska et al. 2002; Di Sabatino et al. 2013). The extent or magnitude of these problems can be difficult to gauge, but Foody (2015), in a comparison of ecosystem service assessments based on data with and without a validation procedure to correct for land cover classification errors, found that such errors could lead to absolute differences in results exceeding a factor of two. Similarly, Konarska et al. (2002) calculated ecosystem service value for the conterminous US based on $30 \mathrm{~m}$ land cover data at nearly double that of analysis based on $1 \mathrm{~km}$ data.
Ecosystem services in urban landscapes have remained under-studied until relatively recently, as mainstream ecosystem science and large-scale preservation efforts tended to focus on expansive and biodiverse 'pristine' environments (Chiesura 2004; Kaye et al. 2006; Davies et al. 2013). However, despite their relatively small area $(<3 \%$ of the global terrestrial surface), there is an increasing recognition that urban ecosystems and their services have a disproportionate importance due to their proximity to human activity and occupancy (Grimm et al. 2008). As a consequence, the ecological study of urban environments has increased markedly in recent years, revealing particular challenges resulting from complex fine scale patterns and interactions, a high degree of spatial heterogeneity, and diverse habitat characteristics that are dependent on culture and geography (Pouyat et al. 2002; Alberti 2005; Davies et al. 2011; Dobbs et al. 2014). These challenges are exacerbated when multiple systems and interactions are considered, such that few previous studies of urban ecosystem services have considered multiple services (Haase et al. 2014) and most have been based on coarse scale land use/land cover data with arbitrary characterisation schemes (Derkzen et al. 2015). The complexities of urban landscapes mean that the measuring and modelling of their ecosystem services, as well as relationships between those services, are likely to be highly sensitive to changes in the scale and resolution of input data (Holt et al. 2015). This presents a challenge for modelling urban ecosystem services and an imperative for understanding the nature of this scale dependence.

The degree of difficulty in assessing urban ecosystem services can vary by the service being studied. Even services that are conceptually simple to model require an accurate and appropriate characterisation of urban environments; a task which is not always easy or possible with readily available data. While moderate to coarse resolution (e.g. $>20 \mathrm{~m}$ ) land use/land cover data are often more cheaply and easily available than higher resolution data, these can fail to capture the necessary detail of landscape patterns, urban or otherwise, and produce fundamentally different results than fine scale data when used as model input (Konarska et al. 2002; Haase et al. 2014; Li et al. 2015). Coarser scales may also necessitate a degree of spatial aggregation, which can result in the loss of characteristic spatial heterogeneity. 
In this paper we test the effects of spatial scale on outcomes of modelling urban ecosystem services. To do this we modelled carbon storage, sediment erosion, and pollination in an urban environment using input datasets at relatively high $(5 \mathrm{~m})$ and low $(25 \mathrm{~m})$ resolutions. The modelled services represent three different conceptual approaches; carbon storage being a stock model, sediment erosion a dynamic flow model, and pollination being an ecological model that depends on both stocks and flows. Services were modelled across three urban areas: the towns of Milton Keynes, Bedford, and Luton, UK, which were chosen as collectively they exhibit a high diversity of urban forms. We use as our modelling framework the Integrated Valuation of Environmental Services and Tradeoffs (InVEST), being one of the most widelyused ecosystem service model frameworks available and one accessible to the widest range of potential users (Tallis et al. 2014). The objectives of the study were to test: (1) the sensitivity of ecosystem service model outputs to the spatial resolution of input data, and (2) whether any scale dependencies are consistent across different services and model conceptual approaches. We use these outputs to explore how the benefits of working with fine scale data balance against the added difficulties in computation and data availability relative to more readily-available coarse scale datasets, and to compare spatial patterns and quantifications of potential ecosystem services within the study area when modelled based on the differing assumptions that are associated with input data at different scales.

\section{Data and methods}

Study area

The study area for this project was the combined urban areas of three large towns: Milton Keynes, Bedford, and Luton, UK (Fig. 1). Collectively these towns exhibit a broad range of urban forms and histories, including historic urban centres, areas of industrial expansion and planned new town development. This diversity captures much of the range of urban forms found in the UK. The focus of this study is on urban form and it should be noted that, given the differences in urban form between the three towns, these cannot be considered as replicates in this analysis; rather an extension of a continuum of urban form. For this reason, we concentrate on description of the variation across all the areas rather than statistical comparison between them. This approach allows the results to be more widely applicable to other urban areas across the UK, giving this study a greater relevance than a rigorous study of a single location would have.

Milton Keynes is one of several planned 'new towns' in England built during the late 20th century. It is located in Buckinghamshire, approximately $72 \mathrm{~km}$ northwest of central London $\left(52^{\circ} 0^{\prime} \mathrm{N}, 0^{\circ} 47^{\prime} \mathrm{W}\right)$, and is noteworthy for its unique road layout and urban form. Unlike the radial road network based on a town centre that is common to many UK urban areas, Milton Keynes possesses an approximately $1.2 \mathrm{~km}$ grid road network designed for speed and efficiency of automotive travel (Peiser and Chang 1999). The population of the urban area in 2011 was 229,941, and the town covers an area of $89 \mathrm{~km}^{2}$ with a population density of 2584 inhabitants $\mathrm{km}^{-2}$ (Office for National Statistics 2013). The town is also characterised by a high proportion of green space relative to many urban environments, both along the major roads and interspersed within the various residential areas (Milton Keynes Council 2015).

Bedford, the county town of Bedfordshire $\left(52^{\circ} 8^{\prime} \mathrm{N}\right.$, $0^{\circ} 27^{\prime} \mathrm{W}$ ), originated as a medieval market town. As such, it differs from Milton Keynes by exhibiting a radial road pattern around the town centre like many British urban areas. Its 2011 population was 106,940 and it covers $36 \mathrm{~km}^{2}$, with a population density of 2971 inhabitants $\mathrm{km}^{-2}$ (Office for National Statistics 2013).

Luton, by further contrast, is a larger industrial town typified by extensive industrial parks and nineteenth century residential 'terraces' that make up much of its urban pattern $\left(51^{\circ} 52^{\prime} \mathrm{N}, 0^{\circ} 25^{\prime} \mathrm{W}\right)$. Studied here as the combined Luton/Dunstable urban area, the region has a population of 258,018 and covers an area of $58 \mathrm{~km}^{2}$, with a population density of 4448 inhabitants $\mathrm{km}^{-2}$ (Office for National Statistics 2013).

Taken collectively, the diversity of the three towns encompasses a range of urban forms and population density that represents much of the variation present in the UK, making the results here more general and robust than would be possible in any single urban area. The combined study area, accounting for some additional urban fringe, encompasses an area of approximately $204 \mathrm{~km}^{2}$. 
Fig. 1 Study area location and $5 \mathrm{~m}$ land use/land cover for Bedford, Luton, and Milton Keynes, UK

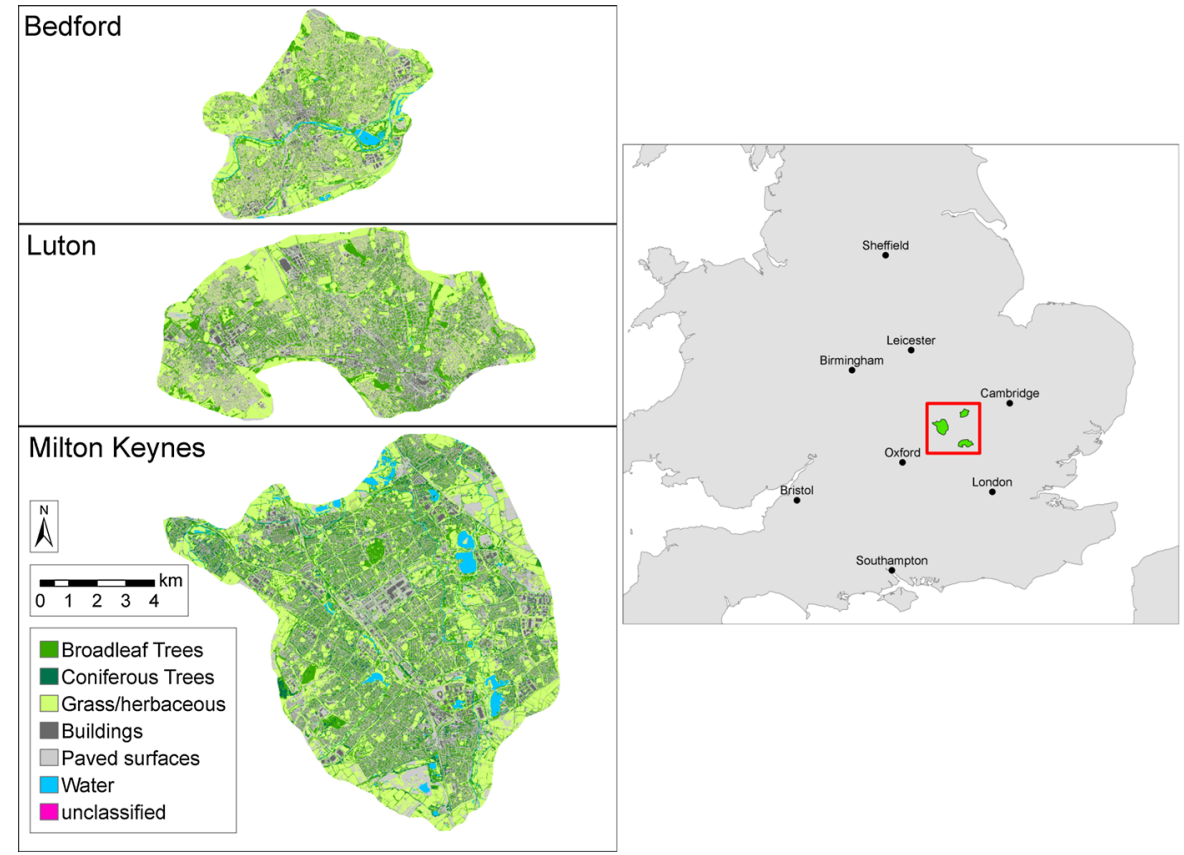

InVEST modelling framework

The InVEST 3.1.0 modelling suite was developed by the Natural Capital Project and Stanford University to provide a framework for estimating and valuing various ecosystem services through a set of standalone but linkable models (Tallis et al. 2014). The InVEST framework currently consists of nine terrestrial models and eight marine models, and is one of the most widely used and accessible options for modelling ecosystem services. For this study three models were chosen according to their functional treatment of ecosystem services; 'Carbon Storage and Sequestration' represents a stock estimation model, 'Sediment Delivery' models flows over the landscape, and 'Pollination' is an ecological model that depends on both stocks and flows. GIS analysis, data organisation, and visualisation were conducted in ArcGIS 10.2 (ESRI 2013).

Land use/land cover and terrain

The fine scale $(5 \mathrm{~m})$ land use/land cover map used in this study was created from colour infrared aerial photography originally at $0.5 \mathrm{~m}$ resolution obtained from LandMap Spatial Discovery (http://landmap. mimas.ac.uk/). The imagery was taken on 2 June 2009 for Bedford; 30 June 2009 and 24 April 2010 for
Luton; and 8, 15 June 2007 and 2 June 2009 for Milton Keynes, based on cloud-free image availability. Buildings and water features were identified from UK Ordnance Survey MasterMap layers, and remaining paved surfaces were separated from vegetation through the use of a Normalised Difference Vegetation Index (NDVI) threshold. Vegetation was then classified into broadleaf trees, coniferous trees, and grass/herbaceous using image segmentation in the software package eCognition (Trimble 2011). To facilitate feasibility of processing and agreement across data types, the land cover map was resampled to $5 \mathrm{~m}$ resolution for all modelling and analysis.

Models were also run using a $25 \mathrm{~m}$ resolution land cover raster from the UK Ordnance Survey (OS), created from a 2007 parcel-based classification of UK land cover (Digimap 2007). This map was chosen to represent widely available datasets that, while not ideal for urban ecosystem service modelling, might in many cases be the best available source for some modellers. While created with a rural focus, this dataset was deemed more appropriate than other common land cover maps such as CORINE due to the coarse resolution of the latter $(100 \mathrm{~m})$, and the belief that such a coarse scale would be unsuitable for accurately depicting important landscape features in the study area (cf. Di Sabatino et al. 2013). Despite the 
rural focus of its origin, the map exhibits a scheme of classification and spatial aggregation in urban lands comparable to other land cover maps at similar and coarser scales such as CORINE. Cover types were parameterised to be as congruent as possible between the imagery-based $5 \mathrm{~m}$ and OS $25 \mathrm{~m}$ classification schemes; similar grassland/herbaceous and agricultural classes in the $25 \mathrm{~m}$ classification were grouped together and parameterised broadly as grass/herbaceous. Additionally, this classification contained a 'suburban' class that the $5 \mathrm{~m}$ map did not. This class had no direct analogue in the $5 \mathrm{~m}$ data, representing an aggregate of paved and vegetated features at too fine a scale to distinguish at $25 \mathrm{~m}$ resolution. This class was therefore parameterised in all three models as an areaweighted average of the parameters used for its constituent classes according to their relative occurrence in the suburban areas of the $5 \mathrm{~m}$ land cover map. Finally, the OS map was chosen over a coarsened version of our own fine-scale map in order to avoid the uncertainty and complex justifications that would have resulted from conducting our own aggregation.

For the sediment erosion model, two digital terrain models (DTMs) were compared as inputs in this study. A relatively course-scale $50 \mathrm{~m}$ resolution DTM was obtained from the UK Ordnance Survey (Ordnance Survey, 2013) and resampled using bilinear interpolation to $25 \mathrm{~m}$ to match the coarse scale land cover map; while a $5 \mathrm{~m}$ resolution bare ground (e.g. buildings and trees removed) DTM, produced from airborne LiDAR was used as the fine-scale input. This was collected by the NERC-ARSF Leica ALS50-II LiDAR instrument and produced by identifying ground returns using LAStools (Isenburg 2015) then interpolating by fitting a 5 th order polynomial over $50 \mathrm{~m}$ by $50 \mathrm{~m}$ patches at $50 \mathrm{~cm}$ resolution. This dataset did not have the exact same coverage available as the OS DTM, so the northwest and southeast corners of Milton Keynes appear clipped in model results based on this dataset. Both DTMs were prepared for hydrological use by the filling of 'sinks' in the data and calculation of watershed basins ('Fill' and 'Basin' tools in ArcGIS Spatial Analyst).

\section{Modelling carbon storage}

The basic data requirements of InVEST's carbon storage model are a raster-based land cover map and data identifying the carbon storage capability in carbon pools for each land cover class in the map. The 5 and $25 \mathrm{~m}$ land cover classifications described above were used and their results compared with one another. Two studies based in Leicester, England, were chosen as the primary sources for data on aboveground (Davies et al. 2011) and soil (Edmondson et al. 2014) carbon storage. Broadleaf and coniferous trees were parameterised the same as one another in model runs to facilitate areal measures and agreement between the data taken from the two papers. The suburban class in the $25 \mathrm{~m}$ analysis was parameterised as an area-weighted average of the vegetated and non-vegetated classes that comprised it in the $5 \mathrm{~m}$ map. Buildings, paved surfaces, and water were all set to zero (Table 1); while non-vegetated classes will contain stored carbon in reality, it is rarely feasible for urban authorities to actively manage carbon sequestration in these locations so it is common practise for them to not be considered in such studies (e.g. Davies et al. 2011; Strohbach and Haase 2012; Jiang et al. 2013; Nowak et al. 2013; Edmondson et al. 2014).

\section{Modelling sediment erosion}

InVEST's sediment erosion model calculates erosion risks and sediment generation and flow based on topography, climate, soil and land cover properties. While the erosion of sediment is itself a negative impact on the landscape, this model was used to represent the inverse of a positive ecosystem service; the ability of urban green space to mitigate erosional losses. The fine-scale run of the model used the $5 \mathrm{~m}$ land cover map and DTM, while the coarse-scale run used the $25 \mathrm{~m}$ land cover map and DTM. Basin maps, also a required input, were calculated separately from the fine and coarse scale DTMs.

Table 1 Model input values for land cover class carbon pools $(\mathrm{Mg} \mathrm{C} \mathrm{ha-1)}$

\begin{tabular}{lll}
\hline Land use/land cover class & Aboveground & Soil \\
\hline Trees & 284.60 & 40.00 \\
Grass & 1.45 & 34.50 \\
Non-vegetated-buildings & 0 & 0 \\
Non-vegetated-other & 0 & 0 \\
Non-vegetated-water & 0 & 0 \\
unclassified & 0 & 0 \\
Suburban (25 m only) & 84.85 & 19.24 \\
\hline
\end{tabular}


Annual soil loss per pixel in the model is calculated according to the revised universal soil loss equation (RUSLE):

soil loss $=R \times K \times L S \times C \times P$

where $R$ is the rainfall erosivity $\left(\mathrm{MJ} \mathrm{mm}(\mathrm{ha} \mathrm{hr})^{-1}\right), K$ is the soil erodibility ( $\mathrm{Mg}$ ha $\left.\mathrm{h}(\mathrm{MJ} \text { ha } \mathrm{mm})^{-1}\right), L S$ is the slope length-gradient factor, $C$ is a crop-management factor, and $P$ is a support practise factor (explained below). Rainfall erosivity $R$ was calculated based on an equation given in the InVEST user manual (Tallis et al. 2014) after guidelines recommended by the FAO, resulting in a value of $190 \mathrm{MJ} \mathrm{mm}$ (ha h year) ${ }^{-1}$. A raster reporting the soil erosivity index $K$ was acquired from the UK National Soil Map (Farewell et al. 2011). Gaps in the source data led to some soil series reporting erroneous $K$ factors below zero; these were replaced with values of zero which the model treated as 'no data' pixels, and removed from subsequent analysis. The cover management factor $C$ was parameterised for each land cover class after Morgan (2005): 0.002 for broadleaf trees; 0.004 for coniferous trees; 0.010 for grassland; 0 for buildings, water and paved surfaces; and 0.003 for suburban ( $25 \mathrm{~m}$ analysis only, as an areaweighted average of constituent classes). The support practise factor $P$ is an index value between 0 and 1 , where 1 has no effect on the equation and values less than 1 represent standard management practices that impede erosion, such as contour farming. Since this parameter is specific to row crop commercial agriculture practices in the United States, it was not applicable here and omitted from the study by assigning it a value of 1 for all classes.

Whereas the RUSLE calculates the amount of eroded sediment lost from each pixel, the sediment delivery ratio (SDR) models the delivery of that sediment to the stream network. The SDR functionality is based on work by Borselli et al. (2008), and is calculated for each pixel $i$ according to the equation:

$S D R_{i}=\frac{S D R_{\max }}{1+\exp \left(\frac{I C_{0}-I C_{i}}{k}\right)}$

where $S D R_{i}$ is the maximum theoretical SDR, $I C$ is a connectivity index after Borselli et al. (2008), and $I C_{O}$ and $k$ are calibration parameters that define the shape of the SDR function. The model's default parameters for threshold flow accumulation (1000), Borselli $k$ parameter (2), Borselli $I C_{O}$ parameter (0.5) and maximum SDR value (0.8) were used according to recommendations in the InVEST user manual (Tallis et al. 2014) after Vigiak et al. (2012).

Finally, the model calculates a sediment retention index for each pixel based on land cover parameters of both the RUSLE and SDR functionality, which represents the avoided soil loss by the current land cover compared to bare soil. A measure of sediment export is produced which represents the combination of these factors; the amount of sediment from each pixel per year that is eroded, not captured and retained by vegetated land cover, and ultimately lost to the stream network. Here total potential soil loss is reported to facilitate comparison with published works, and sediment export is considered as a measure of the potential for urban vegetated land covers to mitigate these losses.

\section{Modelling pollination}

InVEST's pollination model allows the user to input nesting and foraging parameters for multiple pollinator species or species groups, along with nest and flower availability by land cover type for a landscape, to predict the spatial extent over which pollination can be expected to occur within a study area. Here, three species groups were parameterised for their estimated foraging distance and habitat nesting and foraging likelihood in each land cover class according to published literature; honey bees (Beekman and Ratnieks 2000; Garbuzov et al. 2014), bumble bees (Chapman et al. 2003; Charman et al. 2010), and butterflies (Cant et al. 2005). These species groups are not exhaustive of UK pollinators; the objective here was to estimate scale dependence rather than calculate total pollination service provision. Parameters were chosen as rounded estimates based on published ranges (Table 2). As with other models, the process was run on both the 5 and $25 \mathrm{~m}$ land cover data.

\section{Results}

Carbon storage results

Using the $5 \mathrm{~m}$ land cover dataset and the carbon storage values listed previously, the total potential carbon storage for the study area was calculated as $1902.13 \mathrm{Gg}$, equivalent to a mean carbon storage 
Table 2 Parameters for foraging distance, habitat nesting likelihood and foraging suitability for each species group and land use/land cover class

Habitat suitability estimates are given as an index between 0 and 1 where 0 is unsuitable and 1 is maximally suitable

\begin{tabular}{llll}
\hline & Honey bees & Bumble bees & Butterflies \\
\hline Foraging distance $(\mathrm{m})$ & 1000 & 1500 & 200 \\
Broadleaf tree nesting & 1 & 1 & 0 \\
Broadleaf tree foraging & 0.5 & 0.5 & 0.5 \\
Coniferous tree nesting & 0.75 & 0.75 & 0 \\
Coniferous tree foraging & 0.5 & 0.5 & 0.5 \\
Grass nesting & 0.5 & 0.5 & 1 \\
Grass foraging & 1 & 1 & 1 \\
Suburban nesting (25 m only) & 0.41 & 0.41 & 0.36 \\
Suburban foraging (25 m only) & 0.36 & 0.36 & 0.36 \\
\hline
\end{tabular}

density of $9.32 \mathrm{~kg} \mathrm{C} \mathrm{m}^{-2}$ of urban land (Fig. 2). The effects of different land cover classes can be clearly seen in the result maps. The majority of the carbon storage is present in the tree classes, storing an order of magnitude more carbon per unit area than grass/ herbaceous, with the latter class displaying lowmiddle values. At this resolution, the complex patterns blending low and high carbon storage areas are apparent, particularly in residential areas.

For the $25 \mathrm{~m}$ analysis, the total $\mathrm{C}$ result was calculated at $1464.03 \mathrm{Gg}$, equivalent to a mean density of $7.17 \mathrm{~kg} \mathrm{C} \mathrm{m}^{-2}$. These are roughly three quarters of the total and area adjusted values of the highresolution analysis. The same broad relationships with land cover can be seen; however the scale of the classification greatly changes the visible spatial patterns. Differences in patterns between the two maps are most apparent in spatially complex residential regions, where trees, grass, and impervious surfaces were treated separately at $5 \mathrm{~m}$ resolution but aggregated under the suburban class at $25 \mathrm{~m}$ resolution.

\section{Sediment delivery results}

The sediment delivery ratio model used the framework of the revised universal soil loss equation (RUSLE) to calculate annual potential sediment losses from each pixel in the study area, based on its topography and land cover characteristics (Fig. 3). For the three towns, the fine scale model run calculated an average
Fig. 2 Modelled potential carbon storage in Bedford, Luton, and Milton Keynes, $\mathrm{UK}\left(\mathrm{kg} \mathrm{C} \mathrm{m}^{-2}\right)$, based on 5 versus $25 \mathrm{~m}$ resolution land use/land cover

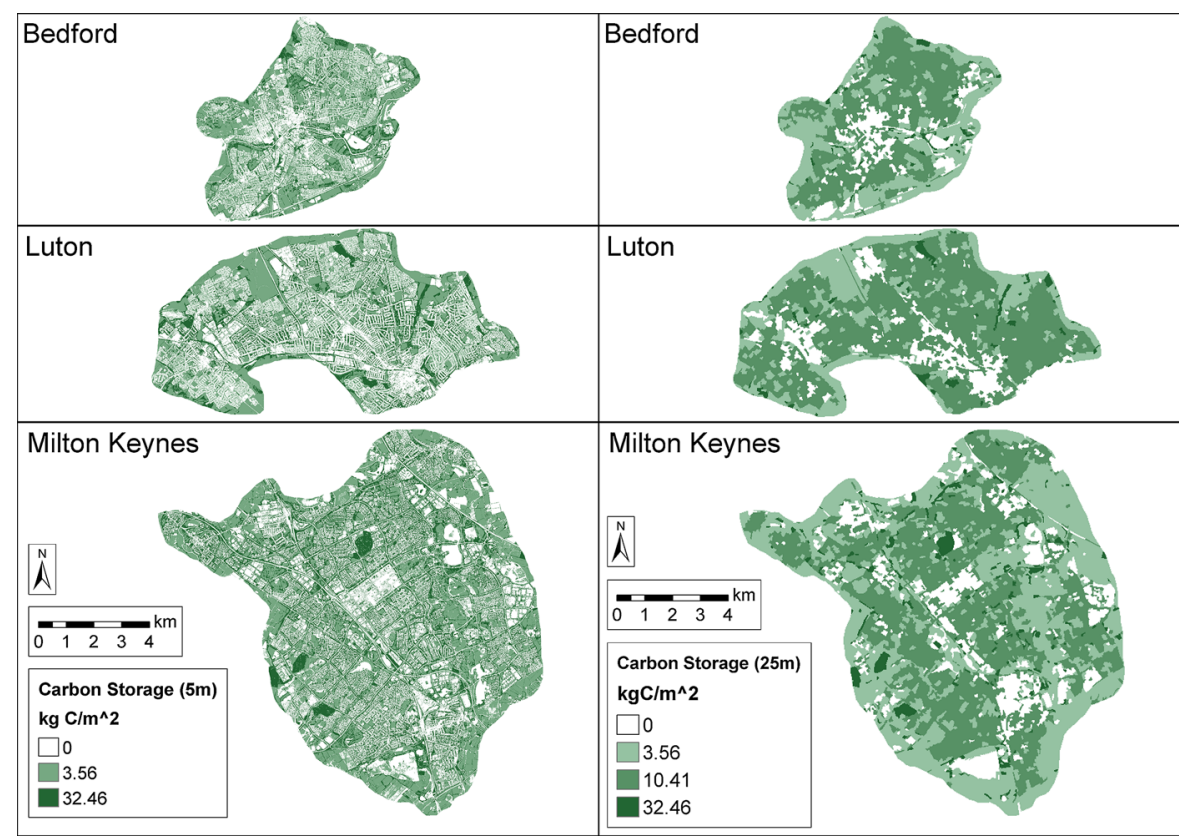


potential soil loss of $6.4 \mathrm{Mg} \mathrm{km}^{-2}$ year $^{-1}$. The coarse scale run by contrast calculated an average soil loss of $18.1 \mathrm{Mg} \mathrm{km}^{-2}$ year $^{-1}$; roughly three times that of the fine scale run.

The fine scale results show a high degree of spatial complexity, subject as they are to the interface of the underlying topographical drainage patterns and the largely heterogeneous patterns of land cover; by contrast, the coarse scale results can be seen to show patterns of soil loss that are much more driven by broad underlying drainage patterns. The coarse scale land cover data contains simpler spatial patterns and greater homogeneity, resulting in erosion patterns that follow the topography of the land with fewer modelled barriers. This underlying topography is also smoother and simpler than in the fine scale data, presenting fewer impediments to surface flow.

Sediment export considers the mitigating effects that topography and land cover have on potential soil erosion and represents net losses to the stream network. Totalled across the study area, the fine scale analysis calculated this net export at $0.31 \mathrm{Mg} \mathrm{km}^{-2}$ year $^{-1}$. Coarse scale analysis calculated the same export at $0.59 \mathrm{Mg} \mathrm{km}^{-2}$ year $^{-1}$. Output maps of sediment export (not shown) exhibited the same spatial characteristics as soil loss described above, but with decreased intensity due to vegetated surfaces acting as both sources and sinks of eroded material.
Pollination results

Pollinator abundance is calculated by InVEST as a relative index value between zero and 1 , based on habitat suitability and proximity to likely nesting sites. The results at different resolutions have been plotted on the same scale to enable visual comparison (0-0.5; neither scale approached the peak index value of 1 ), and the evident differences in pattern show that modelling at different resolutions has a considerable impact on the results. Fine scale results suggest that habitats are more suitable with increasing distance from dense, built-up areas and in larger areas of contiguous green space. Coarse scale results show a similar general interpretation but are more favourable to suburban areas due to their large and continuous occurrence at this scale (Fig. 4). As a measure of this difference, $9 \%$ of the habitat pixels in the $25 \mathrm{~m}$ map exhibited a pollinator abundance index value greater than 0.25 ; in the $5 \mathrm{~m}$ map $6 \%$ did.

\section{Discussion}

\section{Carbon storage}

The potential for urban green spaces to capture and store atmospheric carbon is important amidst steadily
Fig. 3 Potential soil loss $\left(\mathrm{Mg}\right.$ pixel $^{-1}$ year $\left.^{-1}\right)$ in Bedford, Luton, and Milton Keynes, UK, based on $5 \mathrm{~m}$ land use/land cover and digital terrain model versus $25 \mathrm{~m}$ land use/land cover and digital terrain model. Blank spaces denote data gaps in USLE $\mathrm{K}$ factor erosivity input at these locations for which erosion was not calculated. Attribute scale difference between maps is due to differences in pixel size

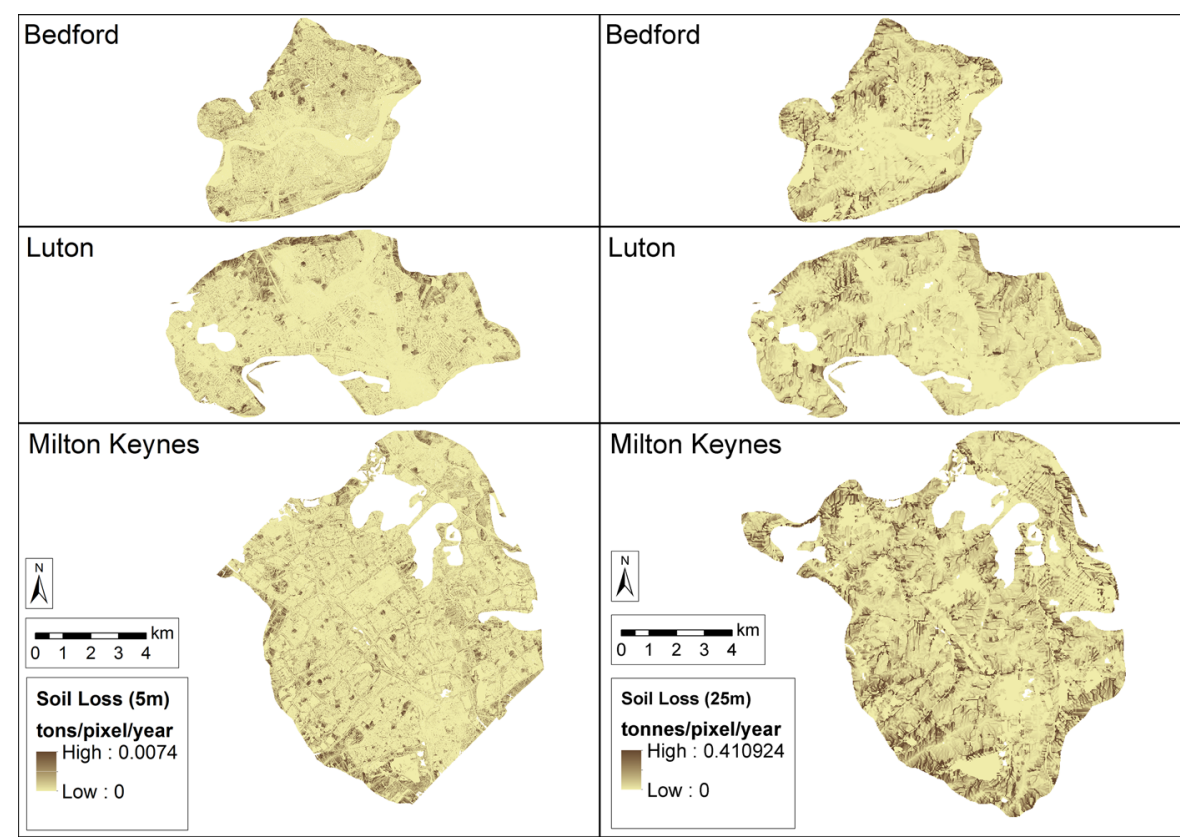




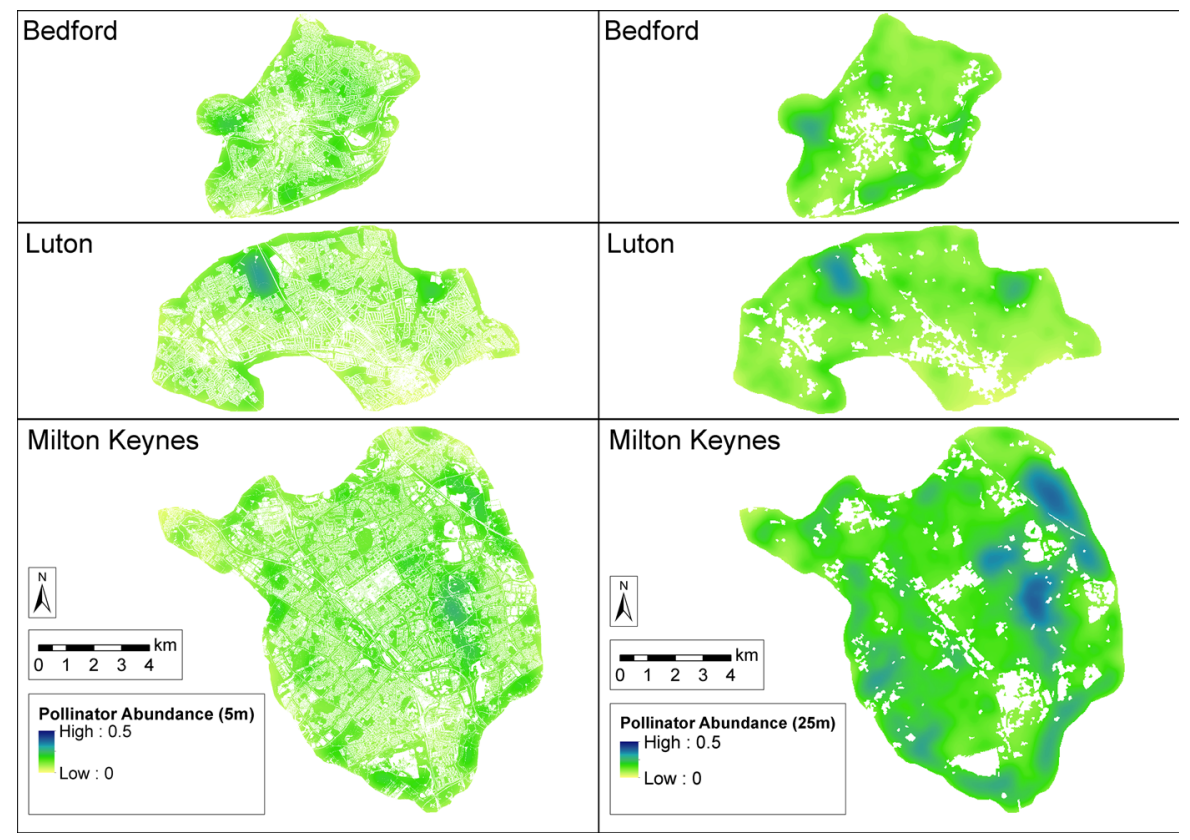

Fig. 4 Relative index of pollination service provision in Bedford, Luton, and Milton Keynes, UK, based on 5 versus 25 m land use/land cover

growing concerns over the role played by anthropogenic $\mathrm{CO}_{2}$ in global climate change. The computations performed by InVEST's carbon storage model are simple relative to process-based carbon cycle models, making a straightforward summation of the input carbon pools for each land cover class in the analysis. However, the ability to quickly visualise and examine spatial patterns of carbon storage across the study area has utility in its capacity to create a visually striking and communicative image showing the "hot spots' for carbon storage within the three towns. Here, these hot spots are clearly the larger woodland areas; however the fine scale maps highlight the importance of residential tree stands as smaller but widely distributed high value patches not present in the coarse scale maps.

When divided by the total study area, a mean storage density of $9.32 \mathrm{~kg} \mathrm{C} \mathrm{m}^{-2}$ of urban land was estimated by the fine scale result. Other studies reported varying amounts of carbon storage ranging from $1.19 \mathrm{~kg} \mathrm{C} \mathrm{m}^{-2}$ in Leipzig, Germany (Strohbach and Haase 2012, only aboveground tree carbon was considered) to $9.81 \mathrm{~kg} \mathrm{C} \mathrm{m}^{-2}$ in rural Dorset, UK (Jiang et al. 2013) due to differences in estimation approaches and urban configurations. By contrast, carbon storage estimates in Leicester, UK combining aboveground (Davies et al. 2011) and soil (Edmondson et al. 2014) storage equated to $8.80 \mathrm{~kg} \mathrm{C} \mathrm{m}^{-2}$; only slightly below the total value modelled here. Such studies suggest that carbon storage is highly variable between cities and it may be problematic to treat one study area as representative of another (Pouyat et al. 2002; Strohbach and Haase 2012; Davies et al. 2013). Greater certainty can be obtained by parameterising models with field-sampled values from within the specific study area, but this is rarely feasible.

The difference between the fine and coarse scale model runs suggests that coarse scale estimates of carbon storage in urban areas may under-predict true values. This is consistent with findings in Davies et al. (2011), where carbon storage in Leicester, UK was modelled based on $0.25 \mathrm{~m}^{2}$ resolution data and found to be an order of magnitude higher than results given by the $1 \mathrm{~km}^{2}$ resolution UK national above-ground carbon storage map. The difficulties in characterising aggregated land cover regions at coarse scales may be a cause of this discrepancy when estimating urban carbon storage. In the current study, fine scale data were available to inform an accurate area-weighted characterisation of the aggregate suburban class. 
Research conducted where only coarse scale data are available would face an increased difficulty in accurately characterising aggregate classes such as this, which can be expected to produce greater error.

\section{Sediment delivery}

The effect of input scale on modelled sediment erosion and export was noteworthy, with the run based on $25 \mathrm{~m}$ data predicting more soil loss on average by a factor of three than the fine scale run $\left(18.1 \mathrm{Mg} \mathrm{km}^{-2}\right.$ year $^{-1}$ vs. $6.4 \mathrm{Mg} \mathrm{km}^{-2}$ year $^{-1}$ ) and more net sediment export from the study area by a factor of two (0.59 $\mathrm{Mg} \mathrm{km}^{-2}$ year $^{-1}$ vs. $0.31 \mathrm{Mg} \mathrm{km}^{-2}$ year $^{-1}$ ). Given that all input factors apart from land cover and terrain were held equal, this difference is entirely due to the scale differences in these two inputs. The $25 \mathrm{~m}$ DTM contained relatively few barriers to runoff, modelling high sediment erosion near any noteworthy stream channels on the map. Large areas of homogeneous cover type in the $25 \mathrm{~m}$ land cover data (predominantly suburban) also had relatively little effect on sediment retention, allowing results to directly reflect the underlying drainage network. The fine scale DTM by contrast presented much more complexity and small barriers to surface flow; restricting areas of high erosion to relatively isolated steep hill slopes. Additionally, the fine scale land cover map contained greater pattern complexity than its coarse scale counterpart. Pockets of grass and tree cover within the urban matrix were modelled to act as further barriers to sediment transport, restricting erosional flow into stream networks to a greater extent than the $25 \mathrm{~m}$ land cover data. Together, this accounted for considerable differences in overall model results. This appears consistent with findings that high habitat complexity can reduce runoff in urban green spaces by an order of magnitude relative to vegetated spaces with low complexity, due to differences in both soil properties and surface cover (Ossola et al. 2015). It also supports the assertion that, under common land use practices in England, urban areas tend to experience less erosion than intensive agriculture (e.g. Collins and Anthony 2008; Collins et al. 2012). This is reflected in the sediment export results as well, which were modelled to be over an order of magnitude less than potential erosion due to the topography of the study area and the ability of vegetated surfaces to capture and retain eroded sediment. This retention ability reflects the underlying ecosystem service of interest here, and the factor of two difference made by the scale of input data further highlights the scale dependencies of the model. The impacts of input scale found here suggest that extreme care should be taken in the selection of appropriate input data when using this type of flow model in complex urban environments.

The large difference caused by input data resolution in this model is striking, but in agreement with past findings concerning the impact that input scale can have on analysis results (e.g. Konarska et al. 2002; Di Sabatino et al. 2013; Li et al. 2015). Few studies of urban soil erosion could be found with which to directly compare results; in most cases studies of stream sediment load for catchments containing urban areas were the closest available analogue. Available results varied heavily but were consistently higher than those found here: Pelacani et al. (2008) estimated 2004 soil erosion in the predominantly agricultural upper Orme stream catchment in Italy at $530 \mathrm{Mg} \mathrm{km}^{-2}$ year $^{-1}$; Pope and Odhiambo (2014) estimated soil loss in a rapidly urbanising watershed in Virginia, USA at $357 \mathrm{Mg} \mathrm{km}^{-2}$ year $^{-1}$; and Angela et al. (2015) estimated erosion in the MagdalenaEslava sub-basin in Mexico City at 'less than' $5000 \mathrm{Mg} \mathrm{km}^{-2}$ year $^{-1}$, presenting this as a low value relative to expectation. Such a large scale difference from the current study is presumably the result of differences in the physical geography of the basin (the authors describe the Magdalena-Eslava sub-basin as possessing steep slopes and fast currents, while rivers in the Milton Keynes/Bedford/Luton area are relatively small) as well as significant differences in climate, land management, and construction practices (Hogan et al. 2014). While available published values are considerably higher than those modelled here, differences in climate, land cover, soil properties and management practices, coupled with uncertainties in the nature and modelling of urban soil erosion, confound valid comparisons.

\section{Pollination}

The importance of models capable of addressing pollination is considerable given recent documented worldwide declines in many pollinator species 
(Carvell et al. 2011; Polce et al. 2013). While primarily developed for agricultural applications, the model was used here in consideration of the benefits of pollination to urban residents. Private and community garden food production as well as landscape greenery all benefit from urban pollinators and the context of the landscape surrounding these sites can have important driving influences on species richness and behaviour (Carvell et al. 2011).

The results of the pollination model were highly influenced by the underlying spatial pattern of the urban landscapes. Under the assumptions of the model, large continuous patches of grassland (e.g. Ouzel Valley Park in Milton Keynes, east of the city centre) were predicted to be the most favourable for urban pollinators and experience the greatest provision of this ecosystem service. This reflects the anticipated effects of habitat connectivity and contiguity that underpins the model's assumptions, and is common in the literature, that pollinators benefit heavily from well-connected, high-quality habitats in close proximity to the desired targets for pollination (Kennedy et al. 2013). By contrast, the mixed landscape of residential land appeared much less favourable, particularly in the fine scale model run. The scale difference was noteworthy, with index values higher across much the study area in the coarse scale results than in the fine scale maps.

The impacts of scale found here relate to how the study area was modelled with respect to the size and suitability of available habitats. Course scale analysis indicated considerably higher overall habitat suitability for pollinators than fine scale, but may overstate the importance of large, contiguous habitat patches relative to smaller patches. While larger habitat patches are believed to be more suitable for pollinator species, pollinators are nevertheless extensively documented as existing within the urban matrix and surviving off relatively small urban habitat patches (Baldock et al. 2015). As such, the fine scale inputs used here may skew the model toward an unrealistically poor result.

Previous research on pollination in the literature has often been conducted at coarse scales more similar to the OS land cover map than the $5 \mathrm{~m}$ dataset used here. Carvell et al. (2011) related field survey data to a UK Ordnance Survey base map at $25 \mathrm{~m}$ resolution to investigate the landscape context in pollination dynamics. Similarly, Kennedy et al.'s (2013) use of the InVEST pollination model and Jha and Kremen's (2013) investigation of pollination across time and land covers near San Francisco, US, both operated on $30 \mathrm{~m}$ resolution land cover data. Moderate to coarse resolutions of 25-30 m therefore appear to be the current norm for such studies, with little research considering finer scales of mapping. For large and predominantly rural study areas this may indeed be appropriate; however greater uncertainty persists regarding the optimal scale of investigation for urban pollinators. Urban landscapes introduce greater complexity, and uncertainties persist in how pollinators make use of habitats in these environments. Continuing research into the relevant spatial scales and land cover dependencies of pollinator dynamics in urban areas will strengthen the utility of such research.

The impact of scale

The comparison of results based on different input data scales highlighted key sensitivities of ecosystem service models that were dependent upon the type of model being run. The carbon storage model represents an ecosystem service based on static stock estimates, and was most sensitive to the landscape characterisation; small but 'high value' landscape features must be accurately represented to ensure valid estimates. The sediment delivery model, by contrast, addresses a dynamic system where flows depend on an accurate representation of the landscape pattern that includes barriers and facilitators. As such, the spatial scale of the data was the most important element. Finally, the pollination model deals with a complex ecological system which depends on both stocks and dynamics; both an accurate landscape characterisation and an appropriate resolution are needed in order to model the system effectively. In all cases the underlying landscape plays a key role; the results of this work suggest the presence of spatial variation in scale dependencies, which may relate to differences in urban form.

As data resolution moves from fine to coarse spatial scales, the ability to distinguish between absolute cover types and resolve small features becomes weaker and categorical classifications necessarily become more aggregate (Ju et al. 2005). The differences in results encountered here highlight how found datasets can force the use of both scales and landscape characterisations that may be sub-optimal for 
modelling a given ecological process. Alternative datasets at coarse spatial scales may be suitable for some work; the $100 \mathrm{~m}$ resolution CORINE land cover classification system has been widely used across Europe for ecosystem service assessments (Van der Biest et al. 2015). However, while more detailed in some landscapes, many of its classes are nonetheless aggregations of vegetated and non-vegetated surfaces, so the same parameterization challenges persist in addition to the increased drawbacks of such a coarse resolution. Coarse-scale datasets such as CORINE remain appropriate for regional to national scale ecosystem services assessments (e.g. national carbon stock inventories), where fine-scale data are likely to introduce computational limitations and an unnecessary degree of complexity. Given the expected or desired outcomes from these models, which, to be informative, will need to be aggregated to meaningful spatial units at the scale of the assessment (e.g. fine scale variation in land form or use will necessarily be lost in regional or national assessments), data at a scale such as CORINE is generally acceptable. Modelling of fine-scale processes and contexts, however, will benefit the most from using fine-scale data. The research carried out here suggests that urban areas exhibit sufficient heterogeneity at fine scales that they should commonly be addressed with appropriately fine-scale data to avoid inaccuracies owing to spatial aggregation. Ultimately, it is fundamental that the scale of inquiry be determined by the nature of the research goal, study area, and ecosystem service of interest, rather than simply being driven by data availability.

The scale dependencies of modelled ecosystem services explored here have implications extending beyond scientific inquiry and into an urban management context. The importance of spatial scale is less apparent when dealing with stock-based models (e.g. carbon storage) than dynamic models (e.g. sediment erosion and pollination), and when concerning large, contiguous habitat patches; a large woodland will possess visibly high ecosystem service value at any scale that can resolve it. However, fine scale mapping has been shown here to possess two key advantages over coarse scale mapping: (1) quantitative assessments of ecosystem service provision over large areas can be expected to produce more accurate results; and (2) it is possible to locate smaller habitat patches of high ecological value ('hotspots') that may be obscured at coarse scales (Holt et al. in press).

\section{Conclusions}

Fine scale datasets can generally be expected to produce better, more accurate results in complex urban environments than coarse data; however they tend to be costly to obtain and may exceed the processing ability of models and equipment. Coarse scale datasets are often more readily available and inexpensive, but may not possess the appropriate scale to accurately represent the complexities of urban landscapes. In modelling ecosystem services an optimal balance must be sought between feasibility and capability. This balance is of particular importance in urban environments given their high complexity over small spatial scales. Crucially, data selection must consider the sensitivities of the services being modelled and prioritise accordingly. For stock estimates, researchers should ensure accurate landscape characterisation; for dynamic flow models, appropriate scale and inclusion of relevant landscape features is vital; for ecological models requiring both stock estimates and flows, both considerations must be balanced. The specifics of the questions being asked, and the nature of the landscape being studied, must inform the process of data selection to determine the most appropriate scales of inquiry.

Acknowledgments This research (Grant Number NE/ J015067/1) was conducted as part of the Fragments, Functions and Flows in Urban Ecosystem Services ( $F^{3} \mathrm{UES}$ ) Project as part of the larger Biodiversity and Ecosystem Service Sustainability (BESS) framework. BESS is a six-year programme (2011-2017) funded by the UK Natural Environment Research Council (NERC) and the Biotechnology and Biological Sciences Research Council (BBSRC) as part of the UK's Living with Environmental Change (LWEC) programme. This work presents the outcomes of independent research funded by NERC and the BESS programme, and the views expressed are those of the authors and not necessarily those of the BESS Directorate or NERC. Thanks to Joanna Zawadzka for much of the assembly and classification of the $5 \mathrm{~m}$ land cover dataset used in this work, Ian Truckell and Toby Waine for technical support with GIS analysis, multiple members of the Natural Capital Project for technical support with InVEST models, and Jane Rickson and Caroline Keay for assistance with data from the UK National Soil Map. The airborne LiDAR data were acquired by NERC Airborne Research and Survey Facility (ARSF) and the team from the ARSF Data Analysis Node at Plymouth Marine 
Laboratory are acknowledged for their support in delivering the LiDAR data and undertaking basic processing.

Open Access This article is distributed under the terms of the Creative Commons Attribution 4.0 International License (http:// creativecommons.org/licenses/by/4.0/), which permits unrestricted use, distribution, and reproduction in any medium, provided you give appropriate credit to the original author(s) and the source, provide a link to the Creative Commons license, and indicate if changes were made.

\section{References}

Alberti M (2005) The effects of urban patterns on ecosystem function. Int Reg Sci Rev 28:168-192

Andersson E, McPhearson T, Kremer P, Gomez-Baggethun E, Hasse D, Tuvendal M, Wurster D (2015) Scale and context dependence of ecosystem service providing units. Ecosyst Serv 12:157

Angela CB, Javier CJ, Teresa GM, Marisa MH (2015) Hydrological evaluation of a peri-urban stream and its impact on ecosystem services potential. Glob Ecol Conserv 3:628-644

Baldock KCR, Goddard MA, Hicks DM, Kunin WE, Mitschunas N, Osgathorpe LM, Potts SG, Robertson KM, Scott AV, Stone GN, Vaughan IP, Memmott J (2015) Where is the UK's pollinator biodiversity? The importance of urban areas for flower-visiting insects. Proc R Soc B Biol Sci 282. doi: $10.1098 /$ rspb.2014.2849

Beekman M, Ratnieks FLW (2000) Long-range foraging by the honey-bee, Apis mellifera L. Funct Ecol 14:490-496

Borselli L, Cassi P, Torri D (2008) Prolegomena to sediment and flow connectivity in the landscape: a GIS and field numerical assessment. Catena 75:268-277

Cant ET, Smith AD, Reynolds DR, Osborne JL (2005) Tracking butterfly flight paths across the landscape with harmonic radar. Proc R Soc B Biol Sci 272:785-790

Carvell C, Osborne JL, Bourke AFG, Freeman SN, Pywell RF, Heard MS (2011) Bumble bee species' responses to a targeted conservation measure depend on landscape context and habitat quality. Ecol Appl 21:1760-1771

Chapman RE, Wang J, Bourke AFG (2003) Genetic analysis of spatial foraging patterns and resource sharing in bumble bee pollinators. Mol Ecol 12:2801-2808

Charman TG, Sears J, Green RE, Bourke AFG (2010) Conservation genetics, foraging distance and nest density of the scarce Great Yellow Bumblebee (Bombus distinguendus). Mol Ecol 19:2661-2674

Chave J (2013) The problem of pattern and scale in ecology: what have we learned in 20 years? Ecol Lett 16:4-16

Chiesura A (2004) The role of urban parks for the sustainable city. Landsc Urban Plann 68:129-138

Collins AL, Anthony SG (2008) Assessing the likelihood of catchments across England and Wales meeting good ecological status due to sediment contributions from agricultural sources. Environ Sci Policy 11:163-170

Collins AL, Zhang Y, McChesney D, Walling DE, Haley SM, Smith P (2012) Sediment source tracing in a lowland agricultural catchment in southern England using a modified procedure combining statistical analysis and numerical modelling. Sci Total Environ 414:301-317

Davies ZG, Edmondson JL, Heinemeyer A, Leake JR, Gaston KJ (2011) Mapping an urban ecosystem service: quantifying above-ground carbon storage at a city-wide scale. J Appl Ecol 48:1125-1134

Davies ZG, Dallimer M, Edmondson JL, Leake JR, Gaston KJ (2013) Identifying potential sources of variability between vegetation carbon storage estimates for urban areas. Environ Pollut 183:133-142

Derkzen ML, van Teeffelen AJA, Verburg PH (2015) Quantifying urban ecosystem services based on high-resolution data of urban green space: an assessment for Rotterdam, the Netherlands. J Appl Ecol 52:1020-1032

Di Sabatino A, Coscieme L, Vignini P, Cicolani B (2013) Scale and ecological dependence of ecosystem services evaluation: spatial extension and economic value of freshwater ecosystems in Italy. Ecol Indic 32:259-263

Digimap (2007) Land cover map 25 m. EDINA digimap ordnance survey service. http://digimap.edina.ac.uk. Accessed on 03 Feb 2014 (Mon 11:32:41 GMT)

Dobbs C, Kendal D, Nitschke CR (2014) Multiple ecosystem services and disservices of the urban forest establishing their connections with landscape structure and sociodemographics. Ecol Indic 43:44-55

Edmondson JL, Davies ZG, McCormack SA, Gaston KJ, Leake JR (2014) Land-cover effects on soil organic carbon stocks in a European city. Sci Total Environ 472:444-453

Elith J, Leathwick JR (2009) Species distribution models: ecological explanation and prediction across space and time. Ann Rev Ecol Evol Syst 40:677-697

ESRI (2013) ArcGIS 10.2. Environmental Systems Research Institute, Redlands

Farewell TS, Truckell IG, Keay CA, Hallett SH (2011) Use and applications of the soilscapes datasets. Cranfield University, Cranfield

Foody GM (2015) Valuing map validation: the need for rigorous land cover map accuracy assessment in economic valuations of ecosystem services. Ecol Econ 111:23-28

Garbuzov M, Schürch R, Ratnieks FLW (2014) Eating locally: dance decoding demonstrates that urban honey bees in Brighton, UK, forage mainly in the surrounding urban area. Urban Ecosyst 18:411-418

Grimm NB, Faeth SH, Golubiewski NE, Redman CL, Wu J, Bai X, Briggs JM (2008) Global change and the ecology of cities. Science 319:756-760

Haase D, Larondelle N, Andersson E, Artmann M, Borgström S, Breuste J, Gomez-Baggethun E, Gren A, Hamstead Z, Hansen R, Kabisch N, Kremer P, Langemeyer J, Rall EL, McPhearson T, Pauleit S, Qureshi S, Schwarz N, Voigt A, Wurster D, Elmqvist T (2014) A quantitative review of urban ecosystem service assessments: concepts, models, and implementation. Ambio 43:413-433

Hogan DM, Jarnagin ST, Loperfido JV, Van Ness K (2014) Mitigating the effects of landscape development on streams in urbanizing watersheds. J Am Water Resour Assoc 50:163-178

Holt AR, Mears M, Maltby L, Warren PH (2015) Understanding spatial patterns in the production of multiple urban ecosystem services. Ecosyst Serv 16:33-46 
Isenburg M (2015) LAStools: converting, filtering, viewing, gridding, and compressing LIDAR data. Rapidlasso $\mathrm{GmbH}$, Gilching

Jha S, Kremen C (2013) Urban land use limits regional bumble bee gene flow. Mol Ecol 22:2483-2495

Jiang M, Bullock JM, Hooftman DAP (2013) Mapping ecosystem service and biodiversity changes over 70 years in a rural English county. J Appl Ecol 50:841-850

Ju J, Gopal S, Kolaczyk ED (2005) On the choice of spatial and categorical scale in remote sensing land cover classification. Remote Sens Environ 96:62-77

Kaye JP, Groffman PM, Grimm NB, Baker LA, Pouyat RV (2006) A distinct urban biogeochemistry? Trends Ecol Evol 21:192-199

Kennedy CM, Lonsdorf E, Neel MC, Williams NM, Ricketts $\mathrm{TH}$, Winfree R, Bommarco R, Brittain C, Burley AL, Cariveau D, Carvalheiro LG, Chacoff NP, Cunningham SA, Danforth BN, Dudenhöffer JH, Elle E, Gaines HR, Garibaldi LA, Gratton C, Holzschuh A, Isaacs R, Javorek SK, Jha S, Klein AM, Krewenka K, Mandelik Y, Mayfield MM, Morandin L, Neame LA, Otieno M, Park M, Potts SG, Rundlöf M, Seaz A, Steffan-Dewenter I, Taki H, Viana BF, Westphal C, Wilson JK, Greenleaf SS, Kremen C (2013) A global quantitative synthesis of local and landscape effects on wild bee pollinators in agroecosystems. Ecol Lett 16:584-599

Konarska KM, Sutton PC, Castellon M (2002) Evaluating scale dependence of ecosystem service valuation: a comparison of NOAA-AVHRR and Landsat TM datasets. Ecol Econ 41:491-507

Li W, Saphores JDM, Gillespie TW (2015) A comparison of the economic benefits of urban green spaces estimated with NDVI and with high-resolution land cover data. Landsc Urban Plann 133:105-117

Milton Keynes Council (2015) Find out more about Milton Keynes. http://www.milton-keynes.gov.uk/jobs-careers/ find-out-more-about-milton-keynes. Accessed on 04 Sept 2015

Morgan RPC (2005) Soil erosion and conservation. Blackwell Publishing, Oxford

Nowak DJ, Greenfield EJ, Hoehn RE, Lapoint E (2013) Carbon storage and sequestration by trees in urban and community areas of the United States. Environ Pollut 178:229-236

Office for National Statistics (2013) 2011 census, Key Statistics for Built Up Areas in England and Wales. United Kingdom Office for National Statistics, London

Ordnance Survey (2013) OS Terrain 50. United Kingdom Ordnance Survey. http://www.ordnancesurvey.co.uk/businessand-government/products/terrain-50.html. Accessed on 23 July 2014
Ossola A, Hahs AK, Livesley SJ (2015) Habitat complexity influences fine scale hydrological processes and the incidence of stormwater runoff in managed urban ecosystems. J Environ Manag 159:1-10

Peiser RB, Chang AC (1999) Is it possible to build financially successful new towns? The Milton Keynes experience. Urban Stud 36:1679-1703

Pelacani S, Märker M, Rodolfi G (2008) Simulation of soil erosion and deposition in a changing land use: a modelling approach to implement the support practice factor. Geomorphology 99:329-340

Polce C, Termansen M, Aguirre-Gutiérrez J, Boatman ND, Budge GE, Crowe A, Garratt MP, Pietravalle S, Potts SG, Ramirez JA, Somerwill KE, Biesmeijer JC (2013) Species distribution models for crop pollination: a modelling framework applied to Great Britain. PLoS ONE 8:e76308

Pope IC, Odhiambo BK (2014) Soil erosion and sediment fluxes analysis: a watershed study of the Ni Reservoir, Spotsylvania County, VA, USA. Environ Monit Assess 186:1719-1733

Pouyat R, Groffman P, Yesilonis I, Hernandez L (2002) Soil carbon pools and fluxes in urban ecosystems. Environ Pollut 116:S107-S118

Schröter M, Remme RP, Sumarga E, Barton DN, Hein L (2015) Lessons learned for spatial modelling of ecosystem services in support of ecosystem accounting. Ecosyst Serv 13:64-69

Strohbach MW, Haase D (2012) Above-ground carbon storage by urban trees in Leipzig, Germany: analysis of patterns in a European city. Landsc Urban Plann 104:95-104

Tallis HT, Ricketts T, Guerry AD, Wood SA, Sharp R, Nelson E, Ennaanay D, Wolny S, Olwero N, Vigerstol K, Pennington D, Mendoza G, Aukema J, Foster J, Forrest J, Cameron D, Arkema K, Lonsdorf E, Kennedy C, Verutes G, Kim CK, Guannel G, Papenfus M, Toft J, Marsik M, Bernhardt J, Griffin R, Glowinski K, Chaumont N, Perelman A, Lacayo M, Mandle L, Hamel P, Chaplin-Kramer R, Vogl AL (2014) Integrated valuation of environmental services and tradeoffs (InVEST) 3.1.0 user's guide. Natural Capital Project, Stanford

Trimble (2011) eCognition Developer 8. Trimble, Munich

Van der Biest K, Vrebos D, Staes J, Boerema A, Bodí MB, Fransen E, Meire P (2015) Evaluation of the accuracy of land-use based ecosystem service assessments for different thematic resolutions. J Environ Manag 156:41-51

Vigiak O, Borselli L, Newham LTH, McInnes J, Roberts AM (2012) Comparison of conceptual landscape metrics to define hillslope-scale sediment delivery ratio. Geomorphology 138:74-88

Wiens JA (1989) Spatial scaling in ecology. Funct Ecol 3:385-397 